book, he takes the common presenting symptoms that we see every day in the general surgical clinics and the emergency rooms - dysphagia, diarrhoea, jaundice, gastrointestinal bleeding and acute abdominal pain, for example and describes their investigation. Being a good clinician, he naturally starts with the clinical study of the patient and then guides us through the complexities, advantages, disadvantages and positive dangers of the almost overwhelming array of modern laboratory and radiological investigations which are now available to us. There are, in addition, chapters on the investigation of fluid and electrolyte balance and postoperative complications which are particularly valuable. Computerized axial tomography (CAT) scanning, which is not generally available yet in this country, is only touched upon in this edition but ultrasound is considered fully and is well illustrated. The text is easy to read, the illustrations clear and the references up to date so that this volume will certainly come to the aid of everyone in the surgical team from chief to house surgeon.

I must confess that I am a biased observer when it comes to reviewing this volume, since it was my privilege and pleasure to read it through from cover to cover while it was still in manuscript form. I certainly found that I had benefited enormously from studying the text with care and I can warmly commend it to my colleagues in surgery.

\section{Medical Acid-Base Balance. The Basic Principles}

By Michael L. G. Gardner. Pp. 125, illustrated, limp cover. Baillière Tindall, London, 1978. £3.95.

There are many books dealing with this topic and it is difficult to see how this one has anything new to offer. It is also difficult to see for whom the book is written. It is essentially an account of acid-base physiology, but far too detailed for a preclinical student. On the other hand clinical diseases in which acid-base balance is abnormal are hardly mentioned. An irritating feature is the repeated references to later sections, giving the reader the impression that he will have to read the book at least twice in order to understand it. Despite these criticisms the text is clearly written, and useful summaries for chapters are given in the appendix.

\section{Reproduction}

British Medical Bulletin Vol. 35, no. 2, May 1979. Scientific Editor, R. V. SHORT. Pp. 112, illustrated. Medical Department, British Council, London, 1979. $£ 5.00$.

The current issue of the British Medical Bulletin, devoted to the subject of reproductive biology (in the words of the Editor 'the science of the transmission of life') is superb. It is also important, for if we are not all to perish we need to know how to limit the transmission of life in our own species and to promote it in those we rely on to feed us. Professor Short points out in his introduction that we cannot rely on putting into practice our currently available information because in reality we lack the kind of basic information that is necessary. But basic information needs basic research and that means the Western 'high technology' approach. And that, of course, is expensive. Professor Short asks whether the highly developed nations of the West will take up the challenge. 'Not on present evidence' seems to be the answer of Dr Aitken who, writing on contraceptive research and development, points out that since 1974 Governmental funding for research in this field has declined in most of the industrialized nations.

That is a depressing introduction to this issue of the British Medical Bulletin but I hope it will not deter readers. The contributors are all internationally recognized experts who have managed to make their information easily understandable and have also transmitted their enthusiasm for their subjects. Obviously a volume like this will be concerned, inter alia, with hormones and there are excellent accounts of the endocrinology of the testis, the ovary, of lactation and lactational infertility, of parturition and of infertility. There are also accounts of meiosis in oöcytes, of chromosomal abnormalities in infertility and of the genetics of sex determination and differentiation. The control of early development, fetal growth and prostaglandins are also discussed. At $£ 5$, this issue of the British Medical Bulletin is incredible value for money.

\section{Surgical Review 1}

Edited by J. S. P. Lumley and J. L. Craven. Pp. viii +407 , illustrated. Pitman Medical, London, 1979. £9.95.

With increasing specialization, there is no doubt that surgeons are experiencing more and more difficulty in keeping abreast of the broad front of surgical progress. Yet few surgeons can be disinterested in the advances which are being made in other branches of their science and art. Indeed, the cross-fertilization between the specialities is a constant source of production of valuable mutations. The stapling machine produced for oesophageal anastomoses may prove just the instrument that the proctologist is looking for in order to carry out a low anterior resection of the rectum.

One way to overcome the problem is to ask a group of enthusiastic specialists to review their own particular fields of interest and to ask them to do this in a lively and perhaps somewhat controversial way. The editors of this volume are to be congratulated on their success. The 22 chapters range over oncology, orthopaedics, vascular surgery, urology and even include an economist's point of view on the costs and benefits of surgery. Although principally aimed at candidates working for their higher surgical diplomas - for which it is eminently suitable - this is certainly a book that can be read with both gain and pleasure by established surgeons who seek an interesting and up-to-date account of surgical progress. We look forward to further reviews in this series at the same excellent standard.

\section{A Textbook of Surgical Pathology}

By Sir Charles Illingworth and the late Bruce J. Dick. 12th edn, Pp. 357, illustrated. Churchill Livingstone, Edinburgh, London and New York, 1979. £15.00.

'Illingworth and Dick' has been a friend of medical students and FRCS candidates for the past 47 years, and through 12 editions and numerous reprints. This is surely a record in medical publishing as throughout that time it has remained under the facile pen of its still young senior author, now emeritus Professor of Surgery in the University of Glasgow. His co-author, Bruce Dick, sadly died in 1967. Sir Charles has always had the praiseworthy facility of being able to speak and to write in clear, precise English. His textbook is a model of brevity. As an example, the subject of Immunity is brilliantly covered in seven and a half pages which give a clear and up-to-date summary of this rapidly advancing field. The illustrations - of macroscopic, microscopic and radiological appearances - are profuse and clear, and there are sufficient references for further reading to enlarge on the major topics.

After opening chapters on response to injury, immunity, wound infection and tumours, succeeding sections cover regional pathology and include a final chapter on gynaecology. As befits the life-time interest of Sir Charles, the section on stomach and duodenum is particularly good.

This attractive volume is warmly commended to students 
and surgical postgraduates. Sir Charles Illingworth has performed a magnificent task in his retirement by keeping this classical contribution as a lively and up-to-date textbook on surgical pathology.

\section{Today's Treatment 3}

Articles Published in the British Medical Journal. Pp. $x i+318$, illustrated. British Medical Association, London, 1979. $£ 5.50$.

This is the third volume of a series and contains articles which appeared in the British Medical Journal in 1977 and
1978. The topics covered are diseases of the respiratory and urinary systems and the use of antibiotics. The chapters on respiratory and urinary diseases (10 and 18 respectively) $\varrho$ provide fairly comprehensive cover. The 12 chapters on $z$ antibiotics are somewhat less successful as there is a mixture $\mathbb{D}$ of chapters, some devoted to specific classes of antibiotics and others to infectious diseases such as meningitis and infective endocarditis. There is an excellent index.

It is, however, remarkable that the amalgamated end- $\mathscr{S}$ product of 38 different authors should be such an easy-toread book with a uniformity of style and emphasis that does $\bar{O}$ great credit to the Editor of the BMJ as well as to the authors. This volume provides valuable practical help for both $\overrightarrow{\mathbb{D}}$ hospital and general practitioners in the management of $\varrho$ everyday clinical conditions. It is warmly recommended. 